\title{
A case of hydrometrocolpos in a neonate
}

\author{
Nimantha Dhananjaya Vithanage ${ }^{1}$, Kapilani Jayasekara ${ }^{1}$, *Imalke Kankananarachchi ${ }^{2}$, Milinda \\ Jayawardena ${ }^{1}$
}

(Key words: Hydrometrocolpos, neonate, ambiguous genitalia, hydroureteronephrosis)

DOI: http://dx.doi.org/10.4038/sljch.v49i1.8910

Sri Lanka Journal of Child Health, 2020; 49(1): 90-93

\section{Introduction}

Hydrometrocolpos is a rare congenital anomaly that is caused by an abnormally dilated vagina/uterus due to obstruction of the genital $\operatorname{tract}^{1}$. Dilatation is caused by fluid that is secreted by the cervical glands under the influence of maternal oestrogen ${ }^{1}$. This can be complicated with hydroureteronephrosis, bowel obstruction and lower limb oedema as a result of compression of the bladder, bowels and venous system. Here we report a case with hydrometrocolpos, ambiguous genitalia, and rectovaginal fistula complicated with bilateral hydroureteronephrosis.

\section{Case report}

A premature baby (34 weeks and 5 days) with ambiguous genitalia was born to a 31-year-old primigravida mother by an emergency lower segment caesarean section (LSCS) due to fetal distress. Baby was resuscitated at birth. Her antenatal period was complicated with polyhydramnios and fetal ultrasound scan showed a large abdominal cyst at the third trimester. Baby required five inflation breaths at birth and the 5 minute Apgar score was 6 and the 10 minute Apgar score was 10 .

The baby was transferred to the neonatal intensive care unit (NICU), Teaching Hospital Karapitiya for further management of underlying problems. Her

\footnotetext{
${ }^{1}$ Teaching Hospital Karapitiya, Sri Lanka, ${ }^{2}$ Faculty of Medicine, University of Ruhuna

*Correspondence: imalke462@gmail.com
}

(D) https://orcid.org/0000-0002-9351-2966

(Received on 25 July 2018: Accepted after revision on 28 September 2018)

The authors declare that there are no conflicts of interest

Personal funding was used for the project.

Open Access Article published under the

Commons Attribution CC-BY (cc) (i) License birth weight was $3.1 \mathrm{~kg}$ and she did not have any facial dysmorphism. Baby had a $1 \mathrm{~cm}$ sized phallus and the urethral meatus was situated in the base of the phallus. Scroto-vaginal folds were empty and bifid (Figure 1). No testicles were found even in the inguinal region. Perineal opening was situated more anteriorly. Straw coloured fluid was drained from both urethra and the perineal opening.

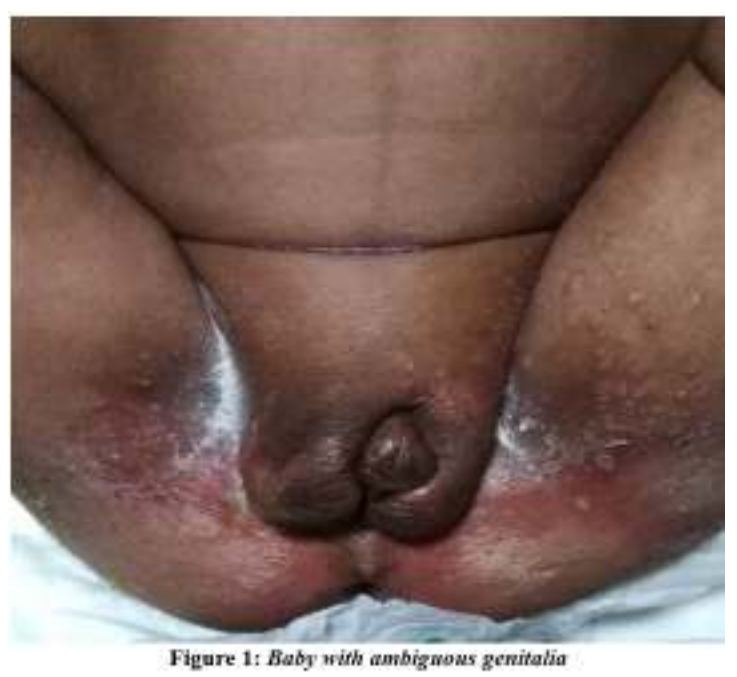

Post-natal ultrasound scan showed bilateral hydroureteronephrosis with a large pelvic mass. There was a difficulty in identifying the bladder, uterus and ovaries. Two 5 French gauge feeding tubes were inserted into urethral meatus and to the perineal opening and around $200 \mathrm{ml}$ of fluid was drained from the perineal opening. Subsequently, magnetic resonance imaging (MRI) of pelvis, micturating cystourethrogram (MCUG), intravenous urogram (IVU) and contrast study via perineal opening were done.

Contrast study through the perineal opening revealed a contrast filling large cystic lesion posterior to the bladder. However, contrast had not entered the rectum. (Figure 2) 


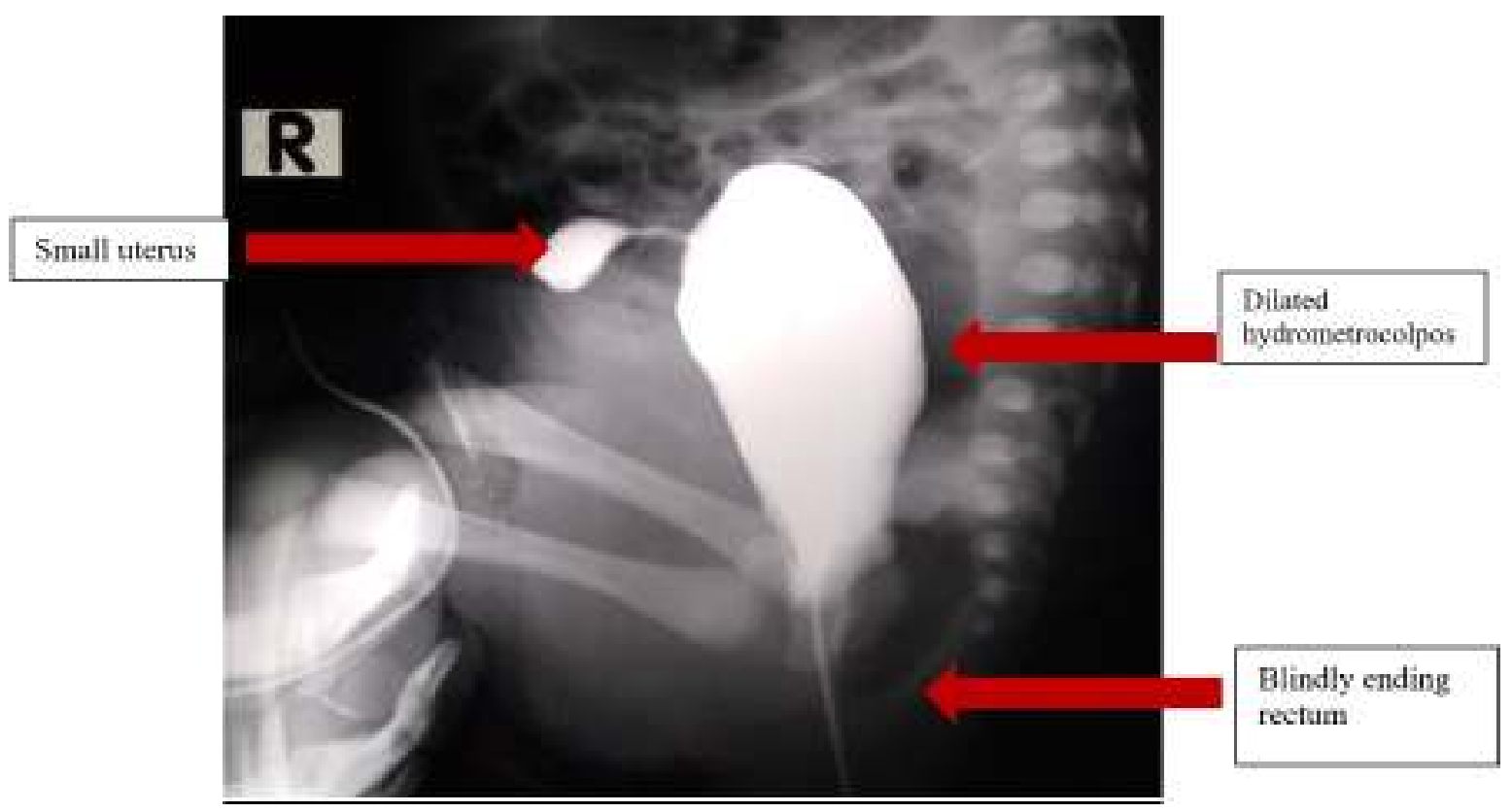

Figure 2: Contrast stady through perimeal opening showing dilated hydrometrocolpos, sumall wteriss and biludly euding rectiom

Contrast study done through the urethral opening showed the anteriorly placed bladder. (Figure 3). Dilated vagina (hydrocolpos) was seen as the large cystic abdominal mass in the magnetic resonance imaging (MRI) of the pelvis and the uterus was seen as a small cystic structure superior to the vagina.
Bladder was anteriorly displaced and was compressed causing bilateral hydroureteronephrosis. The rectum was not opening through an anal orifice and there was a recto-vaginal fistula into which it opened (Figure 4). IVU confirmed the presence of bilateral hydroureteronephrosis (Figure 5).

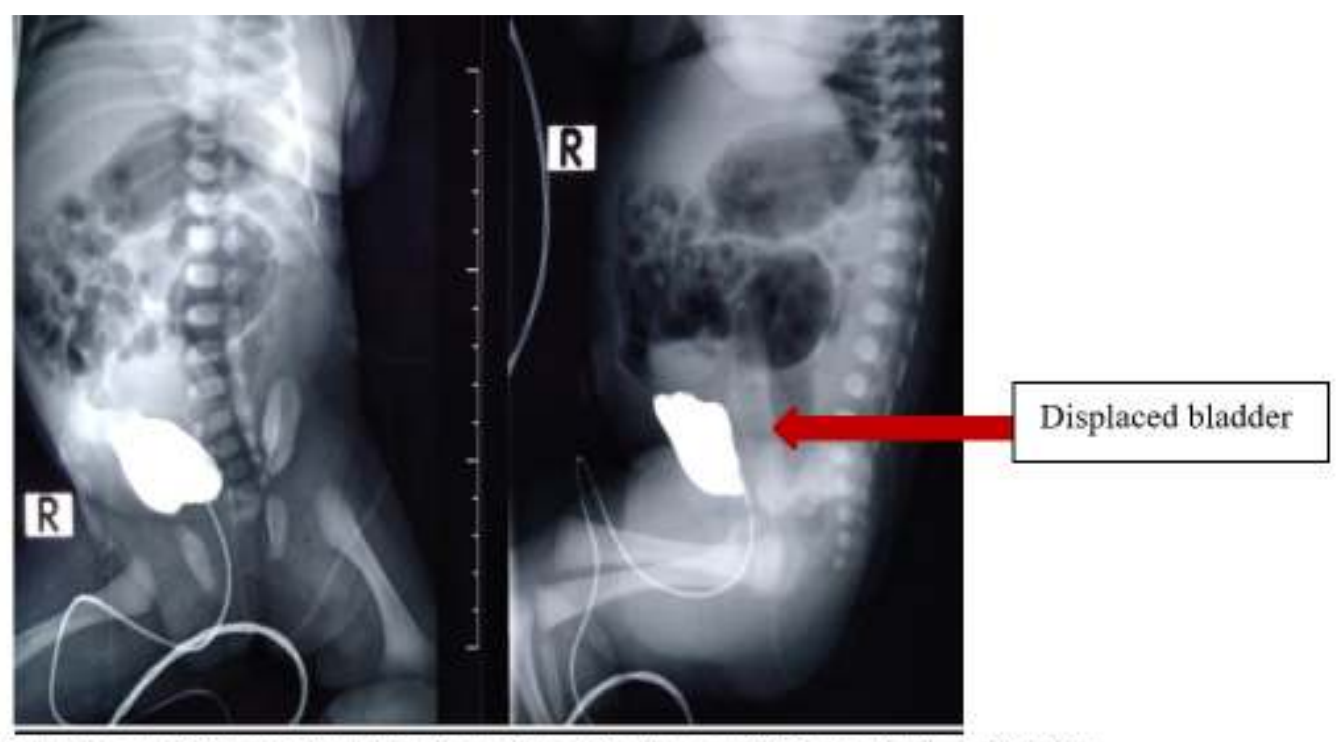

Figure 3: Contrast inserted through urethral opening showing anteriorly displaced bladder 


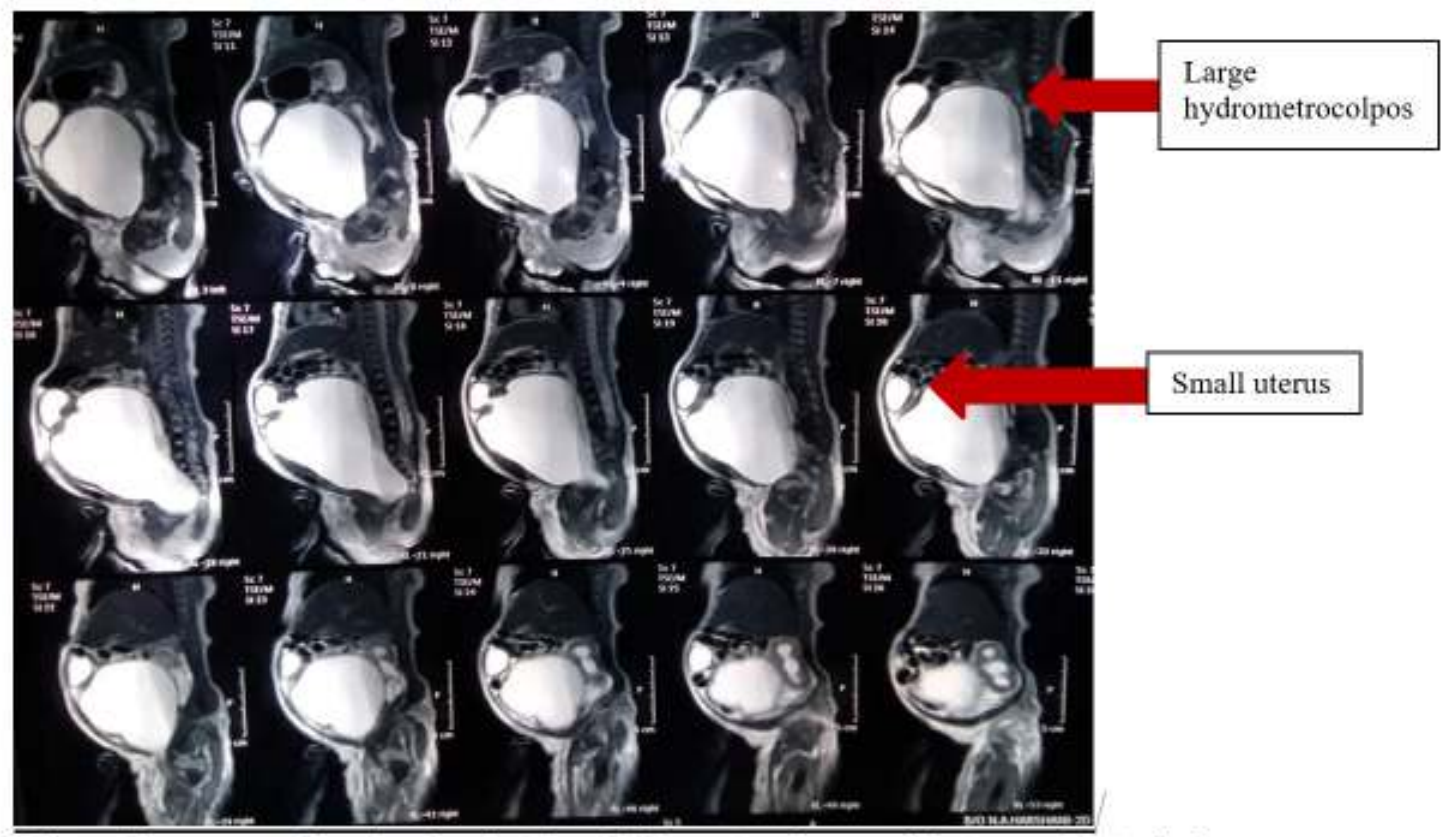

Figure 4: Magnetic resonance imaging showing large hydrometrocolpos, small uterus and anteriorly displaced and compressed bladder

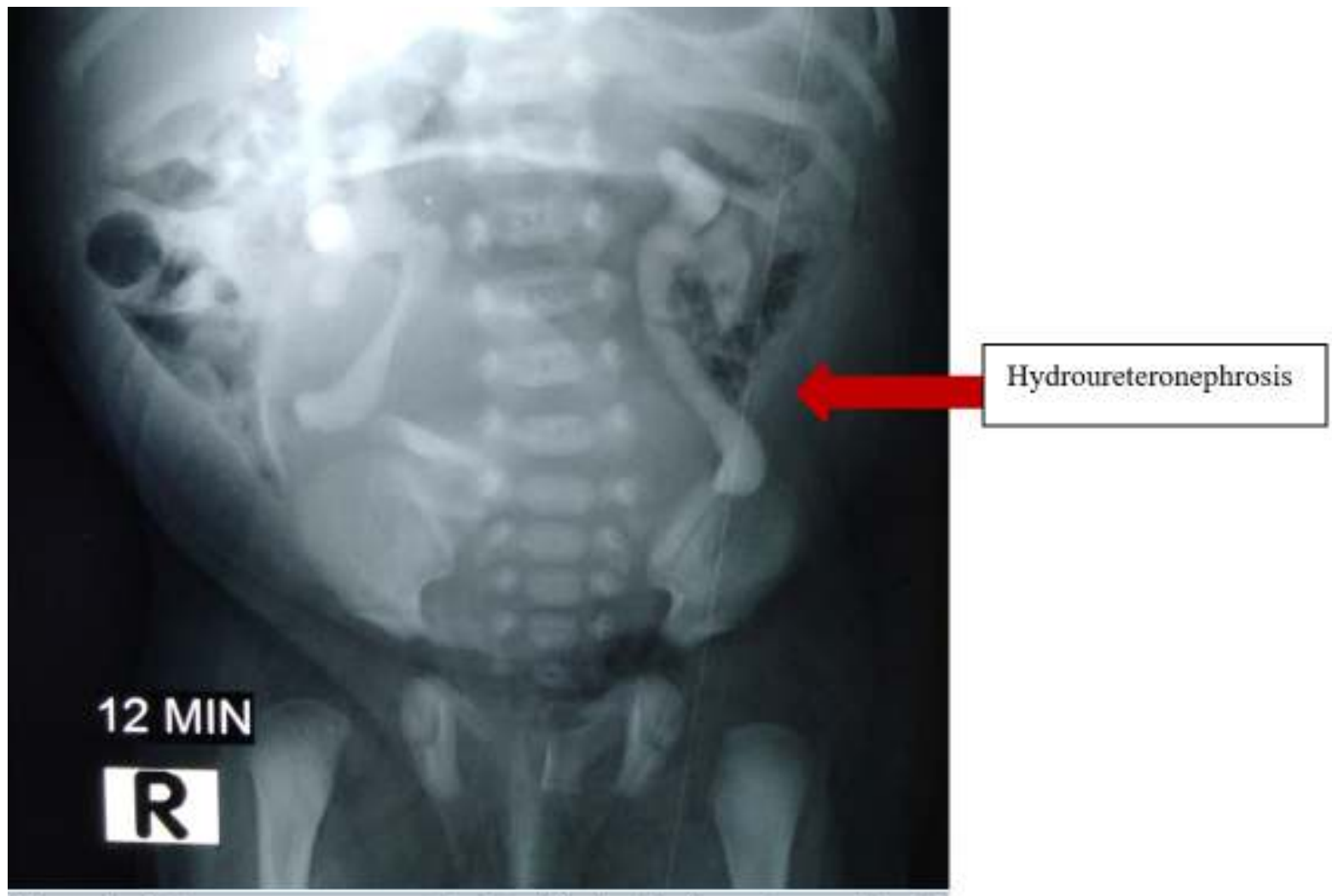

Figure 5: Intravenous urogram showing bilateral hydroureteronephrosis

Colostomy was performed at the age of 6 weeks and the baby is awaiting surgical reconstruction of the genital tract. Karyotyping revealed the genetic sex of the baby as XX. The cause for ambiguous genitalia was not identified and could be a structural malformation associated with hydrometrocolpos. We have excluded congenital adrenal hyperplasia

\section{Discussion}

Hydrometrocolpos is a rare disorder with genitourinary anomalies and a wide range of clinical presentations ${ }^{2}$. Most cases presented in the antenatal period with a pelvic mass in the ultrasound scan (USS). However, it is difficult to make a diagnosis only with an USS, a postnatal MRI being also needed ${ }^{1}$. Hydrometrocolpos is caused by the fluid 
accumulation in vagina due to increased cervicovaginal secretions under the influence of maternal oestrogen ${ }^{1}$. It is also associated with other malformations like imperforate hymen, imperforate anus, renal agenesis, cloacal anomalies, uterine anomalies and urogenital sinus ${ }^{3}$. Most common secondary complication is hydroureteronephrosis due to the obstruction of the bladder from the large mass $^{2}$.

The definitive management requires early drainage of contents in the hydrometrocolpos in order to relieve the hydroureteronephrosis ${ }^{3}$. This could be done as an ultrasound guided procedure ${ }^{3}$. Stepwise surgical correction should be done later depending on the associated anomalies. The overall prognosis in hydrometrocolpos is good ${ }^{4}$. However, pyocolpos, sepsis, hydroureteronephrosis and bowel obstruction can cause increased mortality ${ }^{3}$. Early diagnosis and intervention is the key for better prognosis.

\section{References}

1. Janus C, Godine L. Newborn with hydrometrocolpos and ambiguous genitalia: Clinical significance. Journal of Clinical Ultrasound 1986; 14:739-41.

https://doi.org/10.1002/jcu.1870140915

PMid: 3098799
2. Murthy V, Costalez J, Weiner J, Voos K.Two neonates with congenital hydrocolpos. Case Reports in Pediatrics 2013; 2013: Article ID 692504.

3. Kanso K, Merhi BA, Zeidan M, Ibrahim S, Ghandour F, Iskandarani $\mathrm{F}$, et al. A rare case report of hydrometrocolpos in a female newborn. International Journal of Current Research and Review, 2018; 10(2): DOI. 10.7324/IJCRR.2018.1025

4. Hahn-Pedersen J, Kvist N, Nielsen $\mathrm{OH}$. Hydrometrocolpos: current views on pathogenesis and management. Journal of Urology 1984; 132(3):537-40. https://doi.org/10.1016/S00225347(17)49 726-6 